\title{
O TEMPO DA CRÍTICA
}

\section{Eduardo Dullo ${ }^{1}$}

Resumo: O presente comentário ao texto de Saba Mahmood visa trazer para a discussão a proposta teórica da autora (e também de Talal Asad) que dá sustentação para a formulação da crítica antropológica. Para tanto, tratarei sua abordagem antropológica da secularidade a partir de dois pares de conceitos: tradição e sensibilidade, e tradução e impasse/incomensurabilidade. Terminarei apontando como a proposta teórica de Mahmood (em sua formulação crítica) está em linha de continuidade com a tradição antropológica, e que a sua contemporaneidade deve-se a tensionar as sensibilidade atuais.

Palavras-chave: Saba Mahmood; Talal Asad; Teoria Antropológica; Crítica; Secular.

CRITIQUE'S TIME

\begin{abstract}
This commentary to Saba Mahmood's text aims to discuss how the author's (and Talal Asad's) theoretical position offer a basis for a properly anthropological critique. To accomplish this goal I highlight the two pair of concepts used in analysing secularity: tradition and sensibility, and translation and incommensurability/impasse. The conclusion will suggest that Mahmood's theoretical proposal (in its critical aspect) is both a continuity of anthropological tradition and an innovation of it, this last aspect due to the tensions provoked in current sensibilities.
\end{abstract}

Keywords: Saba Mahmood; Talal Asad; Anthropological Theory; Critique; Secular.

A nossa capacidade de pensar fora deste conjunto de limitaçóes requer necessariamente o trabalho de crítica, um trabalho que não se assenta nas suas pretensôes putativas de superioridade moral ou epistemológica, mas na sua

1 Professor do Departamento de Antropologia e do PPGAS da UFRGS, Brasil. Editor da revista Debates do NER. E-mail: eduardo.dullo@ufrgs.br.

Debates do NER, Porto Alegre, Ano i9, N. 36, P. I i9-I 34, AGo./Dez. 20 i 9 
capacidade de reconhecer e paroquializar seus próprios compromissos afetivos que contribuem para o problema de várias formas. (Mahmood, neste volume).

$\mathrm{O}$ artigo de Saba Mahmood, publicado inicialmente no volume 35, número 4, da Critical Inquiry de 2009 promoveu uma reflexão sobre o debate e o embate que se seguiu à publicação das ilustraçóes em revistas dinamarquesas. Esta reflexão afetou muitos campos e aspectos, como os demais comentários (sobre Islá, mulheres, raça, injúrias e linguagem) publicados neste número da Debates do NER permitem entrever, mas não apenas estes. Desejo neste texto tecer alguns comentários sobre uma questão que não foi objeto de escrutínio público e que é bastante relevante tanto para a Teoria Antropológica quanto para a relação com que os intelectuais e acadêmicos se colocam na cena pública, isto é, a proposta da autora de revisitar a discussão acerca da crítica e atrelar esta com a tradição antropológica. Ao discutir em seu artigo a crítica não mais no singular, mas no plural, Mahmood nos leva a considerar que existem distintas práticas críticas, cada uma possivelmente atrelada a uma tradição e a um estilo de pensamento. Qual seriam, portanto, as práticas críticas próprias da tradição antropológica? E de que maneira o artigo de Mahmood nos permite repensar o que é a antropologia contemporânea se ela se quiser critica?

Este foco na crítica foi a motivação para um evento (e sua publicação em livro, em 2009) posterior à publicação do artigo aqui finamente traduzido. O volume Is critique secular? Blasphemy, injury and free speech é resultado de um evento organizado por Wendy Brown com a participação de duas falas: o artigo de Mahmood e o artigo de Talal Asad Free speech, blasphemy, and secular criticism; ao que se seguiu um diálogo por meio da resposta de Judith Butler, The sensibility of critique: response to Asad and Mahmood e da tréplica de Asad e Mahmood. Podemos dizer que, juntamente com o único artigo de Mahmood já traduzido para o português (pela revista Etnográfica em 2006), em ambos o diálogo com Butler se faz presente e a própria influência da posição antropológica de Asad e Mahmood em Butler é visível 
em inúmeros textos, incluindo o artigo inédito de Butler que publicamos neste presente volume da revista Debates do NER.

$\mathrm{O}$ que faz Mahmood neste artigo? Com quais materiais e dados ela trabalha para produzir uma reflexão antropológica? $\mathrm{O}$ que a torna imersa em uma tradição antropológica consolidada e, ao mesmo tempo, inovadora e contemporânea?

Para além da merecida homenagem que prestamos neste número da Revista, a tradução deste artigo de Mahmood se deve a sua proximidade com temas e tensóes presentes no cenário brasileiro atual. Isto ocorre menos pelo seu foco no Islá e na dinâmica migratória (ainda que a vinda de imigrantes muçulmanos africanos para o Brasil tenha aumentado significativamente nos últimos tempos) e mais ao dedicar-se a repensar antropologicamente o mundo secular — na continuidade do trabalho de Asad (2003). Para tanto, a autora recorta um acontecimento específico de intensa controvérsia: a publicação de ilustraçôes que representam o profeta Maomé de uma maneira que gera reaçóes negativas por parte dos muçulmanos. Temos acompanhado, no Brasil, uma série de eventos que são aproximáveis desta problemática: sejam eles a censura de exposiçóes de arte e de vídeos em canais no YouTube, sejam eles disputas políticas entre religiosos cristãos e posiçôes consideradas não-religiosas ou próprias da laicidade do Estado brasileiro. $\mathrm{O}$ crescimento dos evangélicos, na sociedade e nos cargos representativos no Estado, tem gerado situaçôes de embate cada vez mais frequentes e visivelmente públicos. Nessa direção, pesquisadores brasileiros têm se voltado para estes eventos a partir, sobretudo, do conceito de controvérsia (Giumbelli, 2014; Montero, 2015).

No entanto, a proposta de Mahmood, diferentemente das brasileiras, não formula um conceito analítico de controvérsia. Montero (2015) expóe em sua introduçáo à coletânea (resultado de um projeto coletivo de pesquisa sobre controvérsias públicas), e em meu capítulo (Dullo, 2015) também enfatizo a distinção entre (1) o acontecimento de discordância que gera um embate e (2) a tarefa de pesquisa e análise, a qual envolve uma reflexão sobre quais dados precisam ser levantados e as maneiras pelas quais as posiçóes

Debates do NER, Porto Alegre, ano i9, N. 36, P. il9-I34, Ago./Dez. 20 ig 
são tratadas. Um dos aspectos cruciais nesta diferença analítica, influenciada pela abordagem pragmatista francesa e, sobretudo, por trabalhos de Luc Boltanski, é o cuidado com a posição político-moral do pesquisador ao lidar com um acontecimento que envolve a disputa política de sentidos e significados. Como escrever, falar, em suma, tornar pública a reflexão sem que isto seja uma simplória tomada de posiçáo naquela disputa, mascarada de reflexão acadêmica? Como não se tornar uma simples parte nas controvérsias, dizendo que o lado $\mathrm{A}$ ou $\mathrm{B}$ está errado, mas produzir uma reflexáo que nos permita compreender a situação? Náo se trata de sugerir uma impossível (e/ou indesejável) neutralidade, mas de valorizar o trabalho intelectual e acadêmico da pesquisa e da análise, a partir da qual posiçóes embasadas poderão ser tomadas por qualquer um dos muitos lados das disputas.

Já defendi anteriormente (Dullo, 2016) que determinados recortes de pesquisa são mais interessantes do que outros, pois nos obrigam a repensar nossas práticas intelectuais e os efeitos políticos delas derivados. A análise de controvérsias, como foi feita pelos autores acima mencionados, nos convida a isto pelo simples fato de ser a análise de uma relação. Não se trata de um recorte no qual o pesquisador vá descrever um determinado ponto de vista, demonstrando compreensivamente, de perto e de dentro, o que pensam aquelas pessoas. Por melhor que este trabalho possa ser feito, tal recorte náo tem como foco a relaçáo de dissenso (variando em seu grau de conflito) entre múltiplos pontos de vista - incluindo aí o do pesquisador, que aparece como sujeito num plano de imanência e não como um observador externo e transcendente. Por isso sugeri (Dullo, 2016) que o trabalho da crítica é com frequência dirigido àqueles sujeitos sociais com os quais o pesquisador está em discordância política e/ou moral. O pesquisador critica, portanto, aqueles que não é epistemologicamente capaz de levar a sério. Em contrapartida, tornou-se uma dificuldade para a Antropologia contemporânea assumir uma postura crítica com aqueles que ela busca "levar a sério". Eis uma das muitas questóes que o texto de Mahmood nos convida a pensar: qual a posição de uma antropologia que se pretende crítica? 


\section{ANTROPOLOGIA DO SECULAR/ISMO}

Ao deslocar o eixo de uma alteridade radical para uma antropologia at home, temos visto nas últimas três décadas um aumento significativo de pesquisas que se voltam para aspectos considerados "centrais" da experiência e forma de vida dos países Euro-americanos. Isto inclui, por exemplo, o Estado e o mundo jurídico; a ciência e a tecnologia; e por fim, o secular. Este último aspecto é concebido por Asad como uma episteme e, portanto, como englobante aos exemplos anteriores do Direito e da Ciência. Ao distinguir conceitualmente secular, secularismo e secularidade (ver Dullo, 2012), os domínios da pesquisa são também mais ou menos elásticos. Uma antropologia do secularismo volta-se, prioritariamente, para as maneiras pelas quais são atualizados os projetos e práticas político-ideológicas de sustentação da secularidade e da episteme secular, ao passo que uma pesquisa sobre esta episteme pode ocorrer tendo como objeto a Ciência ou o Direito ao travar relaçóes com seu Outro constitutivo, a Religião. A proposta de Mahmood é, assim, caudatária da proposta de Asad ao não tomar nenhum destes termos como previamente e substancialmente determinados: sáo conceitos relacionais e produzidos discursiva e historicamente a partir de relaçóes de poder e efeitos de verdade. Para investigar o secular/ismo, sugeriu Asad (2003), devemos proceder por desvios e de maneiras indiretas, isto é, fazendo uso das alteridades que circundam esta centralidade da experiência Euro-americana at home. A dificuldade de encarar diretamente esta centralidade fica evidente na pergunta do título do artigo de Charles Hirschkind (2017): Existe um corpo secular? O que faz Mahmood, portanto, é lançar mão de dois pares de conceitos que a permitem estruturar a argumentação. Por um lado, os conceitos de tradiçáo e sensibilidade. Por outro, os de tradução e incomensurabilidadelimpasse.

Em um texto publicado em 2015 na mesma Critical Inquiry (posterior ao texto de Mahmood, portanto), Talal Asad (2017) revisou seu entendimento e abordagem de alguns conceitos, entre eles o de tradição. Proveniente da tradição britânica e marcado por um diálogo com autores franceses como 
Dumont, Bourdieu e Foucault, Asad nâo faz uso do conceito antropológico de Cultura. Diferentemente de Bourdieu, que formulou detalhadamente o que entendia por habitus, campo e capital (entre outros conceitos), Asad apenas tardiamente apresentou a maneira pela qual fez sua abordagem. Entre seus alunos e colegas, entretanto, estas ideias circulavam em aulas e diálogos, razão pela qual tanto o texto de Hirschkind acima citado quanto os de Mahmood, são caudatários dessa abordagem. Partindo de um diálogo com MacIntyre, Asad ${ }^{2}$ afirma que utilizou o conceito de duas maneiras em seus trabalhos:

$[\mathrm{P}]$ rimeiramente, como um espaço teórico para levantar questóes sobre a autoridade, o tempo, o uso da linguagem e a corporização; e, em segundo lugar, como um arranjo empírico no qual a materialidade e a discursividade estão conectadas por meio das particularidades da vida quotidiana. (Asad, 2017, p. 347-348).

O central para Asad é, assim como na proposta de Bourdieu, rejeitar as dualidades que estruturaram o conhecimento social até meados do século $\mathrm{XX}$, isto é, entre representaçóes e práticas, entre subjetivo e objetivo, entre reprodução e mudança. Assim, o conceito de "tradição enfatiza a aprendizagem crítica corporizada, ao invés da teorização abstrata”, de forma que ele utiliza o conceito "para falar tanto do uso da linguagem herdada quanto da aquisição de capacidades incorporadas pela repetição" (Asad, 2017, p. 348). Esta ênfase em uma aprendizagem crítica corporizada difere de muitas abordagens sobre cultura na medida em que tanto o corpo quanto a crítica são percebidas como constitutivas dessas experiências de vir a ser. Como consequência, ninguém está enclausurado, fechado ou limitado (bounded) em sua Cultura, mas as pessoas podem aprender, participar, criticar, rejeitar e deixar uma tradição (inclusive a antropológica). Como ele reforça, "existem diferentes formas de estar articulado à e desarticulado da tradição”, pois “o

2 Este comentário é propositalmente breve, tendo em vista a redação em curso de um texto específico sobre Talal Asad. 
que é aprendido não é uma doutrina (regras), mas um modo de ser" (Asad, 2017, p. 349). Tanto para Asad quanto para Hirschkind e Mahmood, o conceito de tradição enceta a preocupação com o sensório e com um modo de ser, isto é, uma forma de vida corpórea, reunida na ideia de sensibilidade. Porém, a sensibilidade adquire contornos específicos em cada um deles e, no caso de Mahmood, vemos no artigo aqui traduzido como esta ligação é fortemente estabelecida com a linguagem por meio da abordagem da ideologia linguística (ver texto de Daniel Silva, neste volume). A sensibilidade é não apenas um modo de ser individual, mas uma participação na tradição, marcando um processo coletivo no qual as pessoas percebem o mundo de uma determinada maneira. Não se trata de uma (des)conexão entre símbolos, ícones, corpos e suas subjetividades, mas da observação de que cada tradição não apenas (des)vincula de uma forma diferente cada uma destas noçôes, como neste mesmo processo pode atrelar sentidos completamente distintos a cada uma delas. É por isto que Asad propóe, tal como faz Mahmood (2009, neste volume) uma abordagem que faça o contraste e a comparação de tais feixes de relaçóes internos a cada tradição, partindo ao mesmo tempo (e com isso rejeitando a dualidade) da sensibilidade tanto no nível sensório corporal (como em sua análise sobre a tortura e a crueldade, Asad, 2011) quanto no nível da linguagem escrita e formulada em leis, códigos e livros (sobretudo os sagrados para cada tradição como o Al Corão, os Padres da Igreja [Santo Agostinho], e decisões jurídicas).

Este contraste e comparação de duas (ou mais) tradiçóes a partir do seu feixe de relaçóes e da rede de conceitos na qual se estruturam permitiu que tanto Asad quanto Mahmood opusessem a tradição liberal secular à tradição islâmica. A controvérsia que Mahmood analisa neste artigo, portanto, é resultado deste entrar em relação das duas tradições em suas diferenças constitutivas - o que, por sua vez, traz à tona o dissenso e o conflito estabelecido por este mal entendido entre as sensibilidades próprias de cada tradição. A questão de fundo é a mesma que estruturou a tradição britânica da qual Asad (ver 1986) é fruto: a da traduçáo entre diferentes modos de pensar (modes of thought). Para Asad e Mahmood, entretanto, esta tradução ocorre entre modos 
de pensar e de sentir, ou melhor na intraduzibilidade imediata das tradiçôes e suas sensibilidades. Esta dificuldade de tradução ocorre aqui não mais entre um antropólogo britânico e os nativos das colônias, mas numa relação triangular: entre antropólogos não-europeus (ambos ligados ao Paquistão), cidadáos de democracias liberais seculares euro-americanas e a tradição islâmica (seja interna a estes países, seja na figura de imigrantes). O contraponto entre a tradição liberal secular e a tradição islâmica enceta a incomensurabilidade da tradução. $\mathrm{O}$ que faz a pesquisadora é compreender que as partes do conflito não se compreendem ${ }^{3}$ e traçar as razóes para este impasse.

\section{O TEMPO DA CRÍTICA}

$\mathrm{O}$ artigo de Mahmood apresenta uma potente digressão sobre a crítica no espaço destinado às Conclusôes. Quero chamar atenção para este fato por considerar que suas conclusóes são justamente sobre a difícil tarefa da crítica por parte do pesquisador que encara um impasse ou uma situação de incomensurabilidade na tradução entre diferentes sensibilidades e tradiçóes. Considero, também, que suas conclusóes chamam atenção para uma multiplicação da crítica — não mais singular, restrita à tradição do Esclarecimento moderno europeu, mas abrindo para a possibilidade de pensarmos distintas práticas críticas, internas à cada tradição e condizente com distintos estilos de pensamento.

Koselleck (1999) já havia feito a história do desenvolvimento do conceito de crítica na modernidade européia apontando para como esta "arte de julgar" consistiu desde o início em "levar a cabo uma distinção" (p. 93). A trajetória deste conceito é marcada pela autoconfiança da "razáo" na busca pela verdade bem como pela sua suposta condição apolítica, na qual coloca-se acima dos partidos. Ao longo dos séculos XVII e XVIII, mostra-nos Koselleck (1999),

3 A proximidade desta problemática com o trabalho de Sahlins (1990) e Viveiros de Castro (2019) não é mera coincidência. Infelizmente não será possível explorar aqui importantes diferenças entre eles.

Debates do NER, Porto Alegre, ano i9, N. 36, P. I I9-I34, Ago./Dez. 20 i 9 
o desenvolvimento deste sentido de crítica se fez por meio de uma visão de mundo dualista, que opunha inicialmente razão e revelação e, posteriormente, ampliou-se para Estado e Igreja e política e religiaao, de tal modo que

religião e revelação não tem nada em comum com a razão. Desse modo, Bayle traçou uma delimitação que facilitou à época seguinte submeter a religião e a revelação à crítica e, em seguinte, passar à crítica da existência das igrejas em geral. Por um lado, a atividade judicativa da razão repousava nessa delimitação da religião; por outro, traçava essa distinção para criticar a própria religião. (Koselleck, 1999, p. 98).

Separada entre um julgamento no interior do sujeito, no âmbito privado, em Bayle a crítica ainda delimitava um campo próprio, apolítico, o da moral, contrapondo-se à religiáo. É assim que Mahmood nos leva a questionar:

$\mathrm{Na}$ medida em que a tradição da teoria crítica está impregnada de uma suspeita, se não de rejeição, dos compromissos metafísicos e epistemológicos da religião, cabe-nos pensar "criticamente" sobre esta rejeiçấo: como é que a epistemologia e a crítica estão relacionadas dentro desta tradição? Será que tradiçôes distintas de crítica requerem uma epistemologia particular e um pressuposto ontológico do sujeito? (Mahmood, neste volume).

Em compensação, neste momento inicial a crítica ainda se submetia ao Estado. Esta posição mudou com os Iluministas, e, em particular, com Voltaire, quando ela se amplia para tornar-se uma crítica política inclusive ao Estado, ainda que se pretenda acima das disputas partidárias pela sua característica crucial de busca da verdade:

[O]s prós e contras da crítica, que conduzia um processo apolítico no seio da república das letras, tornaram-se, efetivamente, um processo entre o reino da crítica e a autoridade do Estado. Neste processo, os críticos eram ao mesmo tempo os acusadores, a mais alta instância de julgamento e uma das partes. (Koselleck, 1999, p. 101). 
O trabalho de Mahmood, na medida em que explicita que o conflito não ocorre entre uma sociedade (Euro-americana) que detém a verdade racional (secular) e uma população religiosa (muçulmana) que não compreende a liberdade de expressão e o caráter de sátira contida nas ilustrações, mas reformula criticamente esta controvérsia como a falta de compreensão mútua entre duas tradições com ideologias linguísticas próprias, ela paroquializa a tradição liberal, moderna e secular Euro-americana dominante como uma tradiçâo de crítica dentre outras, expondo suas contradiçôes internas. Por exemplo, a própria aporia de uma crítica política que se pretende apolítica e reivindica para si mesma o papel de acusadora, juíza e parte do processo político. O mais curioso, podemos dizer, é que Mahmood faz este movimento reivindicando para a Antropologia (e para si) uma atitude crítica. É importante enfatizar o uma atitude crítica para explicitar que a Antropologia pretende-se em um lugar distinto da tradiçáo crítica Euro-americana traçada por Koselleck. Porém, antes de chegarmos neste ponto, é necessário compreender a proposta de uma atitude crítica e como ela pode ser concebida como uma prática da virtude, isto é, como parte das práticas éticas de cultivo de si (Mahmood, neste volume).

Este movimento, sugiro, é caudatário da proposta de Foucault sobre "o que é a crítica?", na qual ele define a crítica como uma atitude que estabelece "uma certa relação com o que existe, com o que se conhece, com o que se faz, uma relação para com a sociedade, para com a cultura, para com os outros também", de maneira que "a crítica existe somente em relação a outra coisa que ela mesma: é instrumento, meio para um devir ou uma verdade que ela não saberá nem será, ela é um olhar sobre um domínio que quer policiar e não é capaz de fazer a lei" (Foucault, 2000, p. 170). Assim, a atitude crítica é uma relação que se coloca como instrumento para policiar um domínio no qual não se pode fazer a Lei, isto é, o domínio das normas (e, por conseguinte, da moral, como havia pontuado Koselleck). Não é por menos que o texto de Mahmood dedica-se tanto às injúrias morais quanto ao jurídico-legal, pois permite demonstrar como as relaçóes de poder se jogam em ambos os domínios e entre os domínios, seja como crítica racional seja como legalidade 
democrática da maioria (daí suas incursóes sobre a questão da maioria e minoria). Parte do exercício de poder se faz justamente no silenciamento desta dimensão das normas em detrimento da Lei como o único domínio a ser observado, ou seja, o exercício de poder da tradição dominante consiste, também, em silenciar as críticas que são levantadas contra ele:

Para qualquer pessoa interessada em promover uma melhor compreensão no espectro de diferença religiosa, seria importante recorrer não à lei, mas à textura espessa e às tradiçóes de normas éticas e intersubjetivas que proveem o substrato para os argumentos legais (consagrados na linguagem da ordem pública). Neste ensaio, sugeri várias razões pelas quais a ideia de injúria moral que analisei permaneceu invisível e inaudível no debate público sobre os cartuns dinamarqueses, centrais entre elas a incapacidade de traduçáo através de diferentes normas semióticas e éticas [...]. Em última análise, eu diria que o futuro da minoria muçulmana na Europa depende náo tanto de como a lei pode ser expandida para acomodar suas preocupaçóes, mas de uma transformação mais ampla nas sensibilidades culturais e éticas da maioria da população judaico-cristã, que sustentam a lei. (Mahmood, neste volume).

Ao pontuar que a "ancoragem histórica" da crítica Europeia se fez "historicamente bíblica", "essencialmente jurídica” e na crítica à autoridade em nome da verdade, Foucault afirma que "o foco da crítica é essencialmente o grupo de relaçóes que amarram um ao outro, ou uns aos outros, o poder, a verdade e o sujeito" (Foucault, 2000, p. 173). O que fez Mahmood em seu artigo a não ser questionar as limitações que a tradição secular liberal Euro-americana impôs a este "grupo de relaçôes"?

Reconhecendo a historicidade deste grupo de relaçóes e sua particularidade por meio do contraste com a tradição islâmica, Mahmood fez, também, uma demonstração da falsa oposição entre assimilação e marginalização dos muçulmanos em sociedades europeias como as únicas alternativas existentes. Estruturar o campo de possíveis do sujeito é uma das definiçóes que Foucault (1995) ofereceu para as relaçóes de poder. É crucial para Foucault (e, penso, para Mahmood) que a crítica seja o olhar relacional sobre um 
outro (que tem a capacidade de fazer aquela Lei), de maneira que a relaçáo de poder se faz presente, por este lado, como a "arte da não-servidão voluntária, da indocilidade refletida” (Foucault, 2000, p. 172), isto é, como um contraponto histórico (interno do Esclarecimento europeu) ao processo de governamentalização da vida. Assim, a crítica aparece como a atitude daquele que afirma querer "não ser governado dessa forma e a esse preço" (Foucault, 2000, p. 172), seja essa a atitude das reaçóes muçulmanas a partir de outro grupo de relaçóes entre o poder a verdade e o sujeito, seja a atitude da antropóloga que se recusa a aceitar as limitaçôes e opçóes colocadas para os muçulmanos (assimilação ou marginalização), demonstrando a ausência no debate público "[d]a questão da traduzibilidade de práticas e normas através de diferenças semióticas e éticas” (Mahmood, neste volume). É hora de retomarmos o trecho utilizado como epígrafe:

A nossa capacidade de pensar fora deste conjunto de limitaçóes requer necessariamente o trabalho de crítica, um trabalho que não se assenta nas suas pretensôes putativas de superioridade moral ou epistemológica, mas na sua capacidade de reconhecer e paroquializar seus próprios compromissos afetivos que contribuem para o problema de várias formas. (Mahmood, neste volume).

Mahmood procede um ataque em duas frentes complementares: por um lado, ela questiona o "não-pensamento em nome do normativo" (Butler, 2015); por outro lado, ela não assume a posição crítica em sua aporia de apolítica que julga politicamente os demais. A crítica que Mahmood reivindica é própria de uma terceira tradição, a tradição antropológica, sobretudo em sua vertente pós-colonial, objetivando questionar a universalidade dos pressupostos epistemológicos Ocidentais e paroquializar seus compromissos afetivos. $\mathrm{O}$ primeiro ataque sugere que "para aqueles de nós interessados em outras formas de compreender o problema, talvez seja necessário repensar as estruturas avaliativas envolvidas em tais impasses" (Mahmood, neste volume), ou seja, cabe à análise perceber que "o enquadramento binário pressupóe saber tudo o que se precisa saber antes de qualquer investigação efetiva sobre 
essa realidade cultural complexa" (Butler, 2015, p. 206). A atitude crítica entendida como prática ética do cultivo de si, ou, como colocou Foucault, é uma virtude do pensamento e da recusa de ser governado por enquadramentos previamente estabelecidos sem que o sujeito exerça o imperativo de ousar conhecer. Manter-se sob este governo é,

pois, de uma forma de não pensamento, ratificada por um modelo restritivamente normativo, um modelo que necessita de um mapa de realidade capaz de assegurar um julgamento mesmo que esse mapa seja evidentemente falso. Na verdade, é uma forma de julgamento que falsifica o mundo com o propósito de reforçar o próprio julgamento moral como sinal de certo privilégio e de certa 'perspicácia' culturais, uma maneira de manter as hordas a distância. (Butler, 2015, p. 206-207).

O segundo ataque segue desse colocar-se em relação distanciada com o enquadramento normativo, de olhar ao mesmo tempo de dentro (para compreender) e de fora (para situá-lo historicamente). É ao colocar-se nesta relação que reside a atitude crítica, mas a particularidade a ser ressaltada aqui é como a tradição antropológica nos permite fazer tal movimento. Mencionei no início que Mahmood (e outros, no Brasil) tem focado nas controvérsias envolvendo religião e pressupostos seculares. Este foco tem o mérito de evidenciar a relação entre sujeitos distintos, e o conflito e/ou desentendimento de seus pressupostos. Porém, quem faz isso é um terceiro, que também se coloca em relação. A antropóloga, em sua atitude crítica, é aquela que se coloca propositadamente numa relação de exterioridade com ambos, ou melhor, coloca-se em relação com a relação estabelecida entre ambos. Sua empatia e sua crítica é direcionada às duas tradiçôes, suspendendo temporariamente a ação política com o objetivo de, primeiro, compreender.

É a tradição antropológica da tradução entre diferentes sujeitos que reaparece aqui transformada: não mais o antropólogo branco euro-americano secular observando o nativo religioso e/ou mágico das colônias e traduzindo-o para seus pares; é agora uma antropóloga que explicita o impasse e a incomensurabilidade que dificulta a tradução entre o sujeito secular liberal 
e o sujeito religioso muçulmano, uma antropologia que é eminentemente comparativa: ela compara "conceitos (representaçóes) entranhados em sociedades diferencialmente localizadas no tempo e no espaço” (Asad, 2003, p. 17, tradução nossa) ou, quem sabe, compara diferentes ontologias, explicitando o grupo de relaçóes entre o sujeito, a verdade e o poder. É por isso que o central no trecho de Asad é sua continuação: "O importante nesta análise comparativa não é sua origem (ocidental ou não ocidental), mas as formas de vida que os articulam e os poderes que são permitidos ou impedidos por eles." (Asad, 2003, p. 17, tradução nossa). Se, como colocou Viveiros de Castro (2019, p. 250, grifo do autor), "[c] ontrolar esta comparação tradutiva entre antropologias é precisamente no que consiste a arte da antropologia", o artigo de Mahmood é, ao mesmo tempo, clássico e inovador desta arte da antropologia.

O último parágrafo de seu texto, por fim, remete tanto para uma defesa da vida intelectual universitária (que se faz cada vez mais necessária no nosso momento histórico) quanto para um alargamento disciplinar (veja, por exemplo, Robbins, 2006) e de diálogo entre tradiçóes (por exemplo, Furani, 2019). Infelizmente ela não estará por aqui para continuar este caminho. Cabe a nós pensarmos nas rotas e nas maneiras que desenvolveremos de cultivar esta virtude.

\section{REFERENNCIAS}

ASAD, Talal. Formations of the secular: Christianity, Islam, modernity. Stanford: Stanford University Press, 2003.

ASAD, Talal. Pensando sobre tradição, religião e política no Egito contemporâneo. Política e Sociedade, Florianópolis, v. 16, n. 36, p. 347-402, 2017. ASAD, Talal. Reflexões sobre crueldade e a tortura. Revista PENSATA, São Paulo, v. 1, n. 1, p. 164-187, 2011. 
ASAD, Talal. The concept of cultural translation in British Social Anthropology. In: CLIFFORD, James; MARCUS, George (org.). Writing culture: the poetics and politics of ethnography. Berkeley: University of California Press, 1986. p. 141-164.

BUTLER, Judith. O não-pensamento em nome do normativo. In: BUTLER, Judith. Quadros de Guerra: quando a vida é passivel de luto? Rio de Janeiro: Civilização Brasileira, 2015. p. 197-232.

DULLO, Eduardo. Artigo bibliográfico após a (antropologia/sociologia da) religião, o secularismo? Mana, Rio de Janeiro, v. 18, n. 2, p. 379-392, 2012. DULLO, Eduardo. Política secular e intolerância religiosa na disputa eleitoral. In: MONTERO, Paula (org.). Religiöes e controvérsias públicas: experiências, práticas sociais e discursos. São Paulo: Terceiro Nome; Campinas: Unicamp, 2015. p. 27-47.

DULLO, Eduardo. Seriously enough? Describing or analysing the native(s)'s point of view. In: CARRIER, James (org.). After the crisis: anthropological thought, neoliberalism and the aftermath. London: Routledge, 2016. p. 133-153.

FOUCAULT, Michel. O que é a crítica? (Crítica e Aufklärung). Cadernos da Faculdade de Filosofia e Ciências, São Paulo, v. 9, n. 1, p. 169-189, 2000. FOUCAULT, Michel. O sujeito e o poder. In: DREYFUS, Hubert; RABINOW, Paul. Michel Foucault. uma trajetória filosófica. Rio de Janeiro: Forense Universitária, 1995. p. 231-249.

FURANI, Khaled. Redeeming Anthropology: a theological critique of a modern science. Oxford: Oxford University Press, 2019.

GIUMBELLI, Emerson. Simbolos religiosos em controvérsias. São Paulo: Terceiro Nome, 2014.

HIRSCHKIND, Charles. Existe um corpo secular? Religiäo e Sociedade, Rio de Janeiro, v. 37, n. 1, p. 175-189, 2017. 
KOSELLECK, Reinhart. Crítica e crise: uma contribuição à patogênese do mundo burguês. Rio de Janeiro: EDUERJ: Contraponto, 1999.

MAHMOOD, Saba. Religious reason and secular affect: an incommensurable divide? Critical Inquiry, Chicago, v. 35, n. 4, p. 836-862, 2009.

MAHMOOD, Saba. Teoria feminista, agência e sujeito liberatório: algumas reflexôes sobre o revivalismo islâmico no Egipto. Etnográfica, Lisboa, v. 10, n. 1, p. 121-158, 2006.

MONTERO, Paula (org.). Religióes e controvérsias públicas: experiências, práticas sociais e discursos. São Paulo: Terceiro Nome; Campinas: Unicamp, 2015.

ROBBINS, Joel. Anthropology and Theology: an awkward relationship? Anthropological Quarterly, Washington, DC, v. 79, n. 2, p. 285-294, 2006. SAHLINS, Marshall. Ilhas de história. Rio de Janeiro: Jorge Zahar, 1990. VIVEIROS DE CASTRO, Eduardo. A antropologia perspectivista e o método da equivocação controlada. Aceno: revista de Antropologia do Centro-Oeste, Cuiabá, v. 5, n. 10, p. 247-264, 2019.

Recebido em: 29/10/2019

Aprovado em: 29/10/2019 



\section{DOSSIÊ TEMÁTICO}

